\title{
How The Ethical Catastrophe Of Transplanting A Second Set Of Organs In Jessica Santillan After She Suffered Brain Damage Should Lead To Reform In The Donation System
}

\author{
By: Jennifer S. Bard J.D., MPH \\ Assistant Professor \\ Institute for the Medical Humanities \\ University of Texas Medical Branch
}

Citation: J. S. Bard : How The Ethical Catastrophe Of Transplanting A Second Set Of Organs In Jessica Santillan After She Suffered Brain Damage Should Lead To Reform In The Donation System . The Internet Journal of Law, Healthcare and Ethics. 2003 Volume 1 Number 2

News is trickling out of North Carolina that doctors at Duke Medical Center were aware that Jesica Santillan suffered brain damage as a result of her first botched organ transplantation. Of all the mistakes the hospital made in her care, starting with transplanting incompatible organs and ending with refusing the family's request for a second opinion before removing life-support, the decision to give her a second set of organs is the most shocking from an ethical perspective. There is a critical shortage of donor organs. On average in the United States 17 patients die every day while waiting for an organ. In 2001 6,251 individuals died while on the US organ transplant waiting list. As of this week there are 80,541 people waiting for an organ transplant.

Organ distribution is contracted by the government to the United Network for Organ Sharing ("UNOS"). UNOS maintains a national computer network linking all organ procurement organizations and transplant centers. All patients referred by a doctor for transplant are entered into a data- bank. When an organ comes available anywhere in the country the computer generates a ranked list of candidates. The ranking is based, among other things, on blood-type, time on waiting list and urgency of need. Although not explicit it is understood that UNOS works to match organs with those patients in the most need and, this is important, with the most chance of benefiting from a transplant. It is not unusual for a patient to be suspended from the list because he or she is too ill.

While the process of distributing organs is national, there is no such list of organ donors. Nor is there any uniform system for recruiting donated organs. The resulting gap between supply and demand results amplifies the tragedy of the mistakes made by Duke in giving Jesica a second set of organs. 
Looking beyond the botched organ selection, the very process of a heart/lung transplant is dangerous to the brain because its oxygen supply is vulnerable to interruption while on life-support equipment. Jesica lay unconscious for nearly two weeks while her body fought the incompatible organs. It now appears that during this time doctors knew that she had suffered brain damage although were not aware of the extent. The decision to transplant a second set of organs after an initial failed transplant would have been a difficult one in any case. Inevitably Jesica had been so weakened by being on a heart-lung machine during the first transplant that she was a poor candidate for a second surgery. When there was actual evidence of brain damage it was not only medically but ethically wrong to waste a second set of precious organs that might have saved another person's life.

Why did Duke do it? While we don't know, it appears that the intense public criticism of Duke in the Media for the botched transplant led them to make an indefensible second try. In the absence of publicity the standard response would have been to let nature take its course.

When considering the other children waiting for a heart-lung transplant, the decision to squander organs on a brain-dead patient is indefensible. No matter how much Duke regretted its mistake in transplanting incompatible organs, two wrongs do not make a right. Such a public display of unsound decision making when faced with a crisis does not reflect well on Duke or on the organ transplant process.

The tragedy of the wasted organs in Jesica's case is therefore reflective of the critical shortage of donor organs. What can be done to fix the problem? States should pass laws, such as those in some European countries, that presume consent to donate usable organs. Although patients and their families must be able to opt out of donation, the default should be to make the organs available. If the thousands of usable organs wasted every year were harvested, the waiting list would shrink and organ transplant decisions would be based on solid ethical and medical grounds, not on panicked decisions made in celebrated cases. 